\title{
Exigências nutricionais de proteína, energia e macrominerais de bovinos Nelore de três classes sexuais ${ }^{1}$
}

\author{
Marcos Inácio Marcondes ${ }^{2}$, Sebastião de Campos Valadares Filho ${ }^{3}$, Pedro Veiga Rodrigues \\ Paulino $^{3}$, Rilene Ferreira Diniz Valadares ${ }^{3}$, Mário Fonseca Paulino ${ }^{3}$, Fernando Barros \\ Nascimento ${ }^{3}$, Mozart Alves Fonseca ${ }^{3}$
}

\author{
1 Projeto financiado pela Fundação de Amparo à Pesquisa de Minas Gerais (FAPEMIG)/Centro Nacional de Pesquisa (CNPq)/Pronex \\ ${ }^{2}$ Doutorando, DZO-UFV. \\ ${ }^{3}$ Universidade Federal de Viçosa, Viçosa-MG, CEP: 36570-000.
}

RESUMO - Objetivou-se determinar as exigências de energia metabolizável para mantença, as exigências líquidas de proteína, energia e macrominerais para ganho de peso e a eficiência de transformação de exigências líquidas de proteína para ganho em exigências de proteína metabolizável em bovinos Nelore. Foram utilizados 27 animais (nove machos castrados, nove machos não-castrados e nove fêmeas). Três animais de cada classe foram abatidos ao início do experimento como grupo referência. Os 18 animais remanescentes receberam concentrado ( 1 ou 1,25\% do peso vivo) durante 112 dias e foram abatidos ao final, para determinação de sua composição corporal. As exigências líquidas para ganho de peso foram obtidas derivando-se a equação de predição do conteúdo corporal de cada nutriente em função do logaritmo do peso de corpo vazio. As exigências de energia metabolizável para mantença foram estimadas a partir da regressão linear da energia retida em relação ao consumo de energia metabolizável, enquanto a eficiência de uso da proteína metabolizável para ganho de peso foi estimada pela equação da proteína bruta retida em relação ao consumo de proteína metabolizável. As exigências líquidas de minerais estão de acordo com os valores encontrados na literatura. As exigências líquidas de energia para ganho aumentam de acordo com o peso vivo e as exigências líquidas de proteína para ganho diminuem com o aumento do peso. A eficiência de conversão das exigências líquidas de proteína em exigências de proteína metabolizável é de aproximadamente 50\%.

Palavras-chave: bovinos de corte, energia líquida, energia metabolizável, minerais, proteína líquida, proteína metabolizável

\section{Nutrient requirements of protein, energy and macrominerals of Nellore cattle of three genders}

\begin{abstract}
The objective of this study was to determine the metabolizable energy requirement for maintenance and net requirements of crude protein, energy and macrominerals for weight gain, and also the conversion efficiency of net protein requirements to metabolizable protein requirements in Nellore cattle. Twenty seven Nellore animals (nine bulls, nine steers and nine heifers) were used. Three animals of each gender were slaughtered at the beginning of the trial and formed the reference group. The remaining 18 animals received concentrated feed (1.0\% or $1.25 \%$ live weight) and were fed over 112 days. At the end of the trial all the animals were slaughtered to determine the empty body weight and chemical body composition. The net requirements for weight gain were obtained by deriving the body content equation of each nutrient, in function of the log of the empty body weight. The metabolizable energy requirements for maintenance were estimated by a linear regression of retained energy as a function of metabolizable energy intake. The efficiency of converting metabolizable protein into weight gain was estimated by regressing retained crude protein as a function of metabolizable protein intake. Net macromineral requirements were similar to data reported in the literature. Net energy requirements for gain increased with higher live weights and net protein requirements for gain decreased with higher live weights. It was concluded that the conversion efficiency of net protein requirements into metabolizable protein requirements was about $50 \%$.
\end{abstract}

Key Words: beef cattle, macromineral, metabolizable energy, metabolizable protein, net energy, net protein

\section{Introdução}

De acordo com Sainz et al. (2004), a raça Nelore, com mais de 100 milhões de cabeças no Brasil, tornou-se a principal raça destinada à produção de carne, em virtude de sua adaptabilidade às condições de criação em ambientes tropicais (clima quente e úmido, presença de endo e ectoparasitas e padrão de oferta alimentar irregular). 
Portanto, determinar as exigências nutricionais desses animais permite gerar tecnologia de produção adequada às condições brasileiras, notadamente distintas daquelas de países de clima temperado.

Nos bovinos destinados à produção de carne, as exigências de energia de mantença podem corresponder a $70 \%$ das exigências totais da energia dos animais (NRC, 1996). O restante da energia líquida é utilizado para síntese de tecidos, proteína e gordura (Ferrell \& Jenkins, 1985) e é denominado energia líquida de ganho. As exigências de energia para mantença e produção representam são de extrema importância nos sistemas produtivos de carne bovina.

De acordo com o NRC (2000), machos não-castrados são $18 \%$ menos exigentes em energia líquida para ganho que os castrados, que, por sua vez, são 18\% menos exigentes que fêmeas, porém esses dados foram obtidos com animais da raça Angus e em condições diferentes das nacionais.

Dessa forma, objetivou-se com este trabalho estimar as exigências de energia metabolizável para mantença, as exigências líquidas de proteína, energia e macrominerais para ganho e a eficiência de uso da proteína metabolizável em bovinos Nelore de três classes sexuais.

\section{Material e Métodos}

Foram utilizados 27 bovinos Nelore: nove machos castrados, nove machos não-castrados e nove fêmeas, com pesos vivos iniciais de 285,25 $\pm 3,69 ; 293,00 \pm 7,22$ e $264,00 \pm 4,00 \mathrm{~kg}$, respectivamente. Os animais foram confinados em baias individuais providas de comedouros e bebedouros, com área total de $30 \mathrm{~m}^{2}$, dos quais $8 \mathrm{~m}^{2}$ eram cobertos com telhas de amianto e recobertos por piso de concreto. Os animais foram pesados, identificados e vermifugados, e mantidos aproximadamente 30 dias em período de adaptação, recebendo a mesma dieta, constituída de $75 \%$ de silagem de milho e $25 \%$ de concentrado, contendo $12,5 \%$ de PB na MS da dieta.

Após esse período, três animais de cada classe sexual foram abatidos e serviram de referência para estimação da composição corporal inicial. Os 18 animais restantes - seis de cada classe sexual - foram divididos em dois níveis de oferta de concentrado: 1,0 ou 1,25\% do peso vivo. Utilizou-se delineamento inteiramente casualizado, em esquema fatorial $2 \times 3$, composto de concentrado e três classes sexuais, com três repetições.

Os animais foram alimentados duas vezes ao dia, às $7 \mathrm{~h}$ e $16 \mathrm{~h}$, e as rações formuladas para serem isoproteicas (12,5\% PB na matéria seca). Como volumoso foi utilizada silagem de milho, fornecida à vontade. O concentrado foi formulado à base de milho moído, farelo de soja, sal mineral, sal comum, calcário, ureia e sulfato de amônio (9:1). A quantidade de alimento fornecida foi ajustada para que ocorressem 5 e 10\% de sobras, com base na matéria seca total fornecida, com água permanentemente à disposição dos animais.

A relação volumoso:concentrado oferecida foi, em média, 68:32 e 62:38 para as dietas 1 e 2, respectivamente, com base na matéria seca (Tabelas 1, 2 e 3).

A quantidade de ração oferecida e de sobras foi registrada diariamente, por animal, e foram coletadas amostras, também diárias, do volumoso e das sobras. Ao final de cada semana, uma amostra composta foi elaborada e préseca. Posteriormente, foi feita outra amostra composta para o período de 28 dias. Essa amostra foi obtida a partir das amostras compostas semanais, proporcionais ao peso pré-seco total de cada semana. Os alimentos concentrados foram amostrados diretamente na fábrica de rações da UFV, durante a mistura, e, ao final do experimento, foi obtida uma amostra composta (farelo de soja e do milho moído).

Tabela 1 - Proporção dos ingredientes nos concentrados e nas dietas experimentais, com base na matéria seca

\begin{tabular}{lrrrrrr}
\hline Ingrediente & \multicolumn{2}{c}{$1,00 \%$ do PV } & & \multicolumn{2}{c}{$1,25 \%$ do PV } \\
\cline { 2 - 3 } & Concentrado & Dieta & & Concentrado & Dieta \\
\hline Silagem de milho, \% & - & 68,11 & & - & 61,67 \\
Farelo de soja, \% & 18,98 & 6,05 & & 10,88 & 4,17 \\
Milho moído, \% & 74,18 & 23,66 & & 83,41 & 31,97 \\
Calcário, \% & 0,96 & 0,31 & & 1,08 & 0,42 \\
Mistura mineral ${ }^{1}, \%$ & 1,35 & 0,43 & & 0,90 & 0,34 \\
Uréia, \% & 2,60 & 0,83 & & 2,09 & 0,80 \\
Sulfato de amônio, \% & 0,42 & 0,13 & & 0,40 & 0,15 \\
Sal, \% & 1,50 & 0,48 & & 1,24 & 0,47 \\
\hline
\end{tabular}

${ }^{1}$ Composição: Ca - 24,0\%; P - 17,4\%; Co - 100,0 ppm; Cu - 1.250,0; Fe 1.795,0 ppm; Mn - 2.000,0 ppm; Se - 15,0 ppm; Zn - 5.270,0 ppm; I - 90,0 ppm.

Tabela 2 - Composição química dos ingredientes utilizados na ração experimental

\begin{tabular}{lrrr}
\hline Item & $\begin{array}{r}\text { Silagem } \\
\text { de milho }\end{array}$ & $\begin{array}{r}\text { Farelo } \\
\text { de soja }\end{array}$ & $\begin{array}{r}\text { Milho } \\
\text { moído }\end{array}$ \\
\hline Matéria seca (\%) & 26,53 & 88,65 & 85,14 \\
Matéria orgânica (\%MS) & 92,25 & 94,03 & 98,94 \\
Proteína bruta (\%MS) & 5,75 & 49,14 & 8,17 \\
NIDN/N (\% PB) & 20,76 & 6,10 & 21,25 \\
Extrato etéreo (\%MS) & 2,51 & 1,25 & 2,56 \\
FDNcp (\%MS) & 52,62 & 15,84 & 16,33 \\
Fibra em deteregente & 56,43 & 18,93 & 18,44 \\
neutro (\%MS) & & & \\
CNFcp (\%MS) & 31,37 & 27,80 & 71,88 \\
Carboidratos não-fibroso (\%MS) & 27,56 & 24,71 & 69,77 \\
Fibra em detergente ácido (\%MS) & 34,18 & 11,52 & 2,57 \\
Lignina (\%MS) & 4,18 & 0,50 & 0,58 \\
Sílica (\%MS) & 2,77 & 0,00 & 0,17 \\
FDNi (\%MS) & 23,26 & 2,41 & 1,70 \\
Fibra em detergente & 13,46 & 0,86 & 0,72 \\
ácido indigestível (\%MS) & & & \\
\hline
\end{tabular}


Tabela 3 - Composição química dos concentrados e das dietas experimentais

\begin{tabular}{|c|c|c|c|c|}
\hline \multirow[t]{2}{*}{ Item } & \multicolumn{2}{|c|}{$1,00 \%$ do $\mathrm{PV}$} & \multicolumn{2}{|c|}{ 1,25\% do PV } \\
\hline & Concentrado & Dieta & Concentrado & Dieta \\
\hline Matéria seca, \% & 85,78 & 48,34 & 86,01 & 51,91 \\
\hline Matéria orgânica, \% & 94,27 & 93,76 & 95,25 & 94,18 \\
\hline Proteína bruta, \% & 22,71 & 11,40 & 18,03 & 10,68 \\
\hline Extrato etéreo, \% & 2,14 & 2,91 & 2,27 & 2,89 \\
\hline FDNcp, \% & 15,12 & 42,54 & 15,34 & 40,03 \\
\hline $\begin{array}{l}\text { Carboidratos } \\
\text { não-fibrosos, \% }\end{array}$ & 59,02 & 38,37 & 63,38 & 42,06 \\
\hline $\begin{array}{l}\text { Fibra em detergente } \\
\text { neutro indigestível, \% }\end{array}$ & 2,11 & 14,96 & 1,77 & 13,61 \\
\hline $\begin{array}{l}\text { Fibra em detergente } \\
\text { ácido indigestível, \% }\end{array}$ & 1,32 & 8,61 & 0,86 & 7,74 \\
\hline $\begin{array}{l}\text { Nutrientes digestíveis } \\
\text { totais, \% }\end{array}$ & - & 72,15 & - & 72,28 \\
\hline
\end{tabular}

As pré-secagens foram realizadas em estufa ventilada $\left(65^{\circ} \mathrm{C}\right)$ e as moagens, em moinho de peneira de malha de $1 \mathrm{~mm}$. As amostras obtidas foram armazenadas em recipientes de plástico para posteriores análises laboratoriais.

O experimento teve duração de 112 dias, divididos em quatro períodos de 28 dias. Ao final de cada período, os animais foram pesados, sempre após jejum alimentar de sólidos de 16 horas, com o objetivo de monitorar o ganho de peso dos animais e proceder ao ajuste semanal na quantidade de concentrado fornecido. Com base do ganho médio obtido para cada animal no período anterior, o peso vivo foi estimado, ao início de cada semana, e a oferta do concentrado foi corrigida semanalmente.

O abate ao final do experimento foi realizado de forma escalonada e aleatória, sempre com um animal de cada um dos seis tratamentos por dia, totalizando três dias de abate.

Após o abate, o trato gastrintestinal (rúmen, retículo, omaso, abomaso e intestinos delgado e grosso) de cada animal foi esvaziado e lavado. Os pesos de coração, pulmões, fígado, baço, rins, gordura interna, carne industrial, mesentério, cauda e aparas (traqueia, esôfago e aparelho reprodutor), juntamente com os do trato gastrintestinal lavado, foram somados aos das demais partes do corpo (carcaça, cabeça, couro, pés e sangue) para determinação do peso de corpo vazio (PCVZ). A relação média obtida entre o PCVZ e o peso vivo (PV) dos animais-referência foi utilizada para estimar o PCVZ inicial dos animais mantidos no experimento.

O couro retirado durante o abate foi pesado e uma amostra de $400 \mathrm{~cm}^{2}$ foi obtida da região posterior esquerda de cada animal, depois, foi picada e armazenada a $-20^{\circ} \mathrm{C}$ para posteriores análises laboratoriais. Dentro de cada nível de concentrado, foi sorteado um animal, para retirada da cabeça e de dois membros (um anterior e outro posterior).
A cabeça e os membros foram dissecados em couro, tecido mole e osso. O peso do couro obtido na dissecação da cabeça e dos membros foi adicionado ao couro retirado no momento do abate, obtendo-se, assim, o peso total do couro de cada animal. O tecido mole da cabeça e dos pés foi moído, enquanto os ossos foram serrados, amostrados e armazenados para posteriores análises laboratoriais. As composições física e química da cabeça e dos membros obtidas nos animais sorteados dentro de cada tratamento foram utilizadas para a obtenção da composição dos demais animais pertencentes ao mesmo tratamento.

A carcaça de todos os animais foi dividida em duas meias-carcaças, as quais foram pesadas e resfriadas em câmara fria a $-5^{\circ} \mathrm{C}$ durante aproximadamente 18 horas. Decorrido esse tempo, as meias-carcaças foram retiradas da câmara fria e pesadas.

A meia-carcaça direita de cada animal foi totalmente dissecada para separação dos componentes músculo, gordura e ossos, que foram pesados para avaliação da composição física da carcaça. Os tecidos muscular e adiposo foram moídos e o tecido ósseo serrado. Uma amostra representativa de cada componente foi retirada e, posteriormente, foi obtida uma amostra composta de carne + gordura, proporcional ao seu peso na carcaça. Para amostragem do tecido ósseo, os ossos da carcaça foram divididos em três categorias: ossos longos, costelas e vértebras. Cada tipo de osso foi pesado separadamente, retirando-se, proporcionalmente, uma subamostra de cada categoria. As subamostras, depois de homogeneizadas, formaram uma amostra dos ossos da carcaça. Todos os procedimentos descritos acima, desde o abate, foram aplicados aos animais-referência, abatidos no início do experimento.

Os componentes rúmen, retículo, omaso, abomaso, intestino delgado, intestino grosso, gordura interna, mesentério, fígado, coração, rins, pulmão, língua, baço, carne industrial e aparas (esôfago, traquéia e aparelho reprodutor) foram triturados conjuntamente em cutter industrial por 20 minutos e homogeneizados para obtenção de uma amostra, denominada órgãos e vísceras.

As amostras de sangue foram coletadas imediatamente após o abate e a sangria, acondicionadas em recipiente de vidro e levadas à estufa de ventilação forçada $\left(65^{\circ} \mathrm{C}\right)$ durante 48 a 72 horas, para quantificação do teor de MS. Em seguida, foram moídas em moinho de bola e acondicionadas em recipientes para posterior determinação do nitrogênio total, extrato etéreo e dos minerais, conforme descrito por Silva \& Queiroz (2002).

As amostras de órgãos e vísceras (200 g), de músculo + gordura (200 g), de couro (100 g), de ossos (100 g), tecidos mole da cabeça (200 g) e dos pés (100 g) foram acondicio- 
nadas em vidros com capacidade de $500 \mathrm{~mL}$ e levadas à estufa a $105^{\circ} \mathrm{C}$ por 48 a 72 horas, para avaliação da matéria seca gordurosa (MSG). Posteriormente, as amostras foram submetidas a lavagens sucessivas com éter de petróleo, obtendo-se a matéria seca pré-desengordurada (MSPD). Em seguida, foram moídas em moinho de bola, para avaliações dos teores de nitrogênio total, extrato etéreo e cinzas, conforme descrito por Silva \& Queiroz (2002). A gordura removida no pré-desengorduramento foi calculada pela diferença entre a MSG e a MSPD, cujo resultado foi adicionado aos obtidos para o extrato etéreo residual na MSPD, para determinação do teor total de gordura.

Os conteúdos corporais de gordura, proteína e macrominerais foram determinados em relação a suas concentrações nos órgãos e vísceras, no couro, no sangue, na cabeça, nos pés e nas amostras da meia-carcaça esquerda (ossos e músculo + gordura).

As estimativas da energia corporal foram obtidas a partir dos teores corporais de proteína e gordura e seus respectivos equivalentes calóricos, conforme a equação preconizada pelo ARC (1980):

$$
\mathrm{CE}=5,6405 \mathrm{X}+9,3929 \mathrm{Y} \text {, }
$$

em que $\mathrm{CE}=$ conteúdo energético $(\mathrm{Mcal}) ; \mathrm{X}$ = proteína corporal (kg); $\mathrm{Y}=$ gordura corporal (kg).

Os conteúdos de gordura, proteína, energia e macrominerais retidos no corpo dos animais de cada tratamento foram estimados por meio de equações de regressão do logaritmo do conteúdo corporal de proteína, gordura, energia, ou do macromineral específico em função do logaritmo do PCVZ, segundo o ARC (1980), conforme o seguinte modelo:

$$
\mathrm{Y}_{\mathrm{i}}=\mathrm{a}+\mathrm{bX} \mathrm{X}_{\mathrm{i}}+\mathrm{e}_{\mathrm{i}}
$$

em que $\mathrm{Y}_{\mathrm{i}}=$ logaritmo do conteúdo total de proteína $(\mathrm{kg})$, gordura (kg), energia (Mcal) ou macromineral $(\mathrm{kg})$ retido no corpo vazio; $\mathrm{a}$ = intercepto; $\mathrm{b}$ = coeficiente de regressão do logaritmo do conteúdo de gordura, proteína, energia ou do macromineral em função do logaritmo do PCVZ; $\mathrm{X}_{\mathrm{i}}=$ logaritmo do PCVZ; $\mathrm{e}_{\mathrm{i}}=$ erro aleatório.

Derivando-se a equação de predição do conteúdo corporal de energia, proteína, ou do macromineral específico em função do logaritmo do PCVZ, foi obtida a equação de predição do conteúdo de energia, proteína ou macromineral por kg de ganho de PCVZ, que corresponde às exigências líquidas de energia, proteína ou do macromineral específico para ganho de $1 \mathrm{~kg}$ de PCVZ, obtidas a partir de equação do tipo:

$$
\mathrm{Y}^{\prime}=\mathrm{b} \cdot 10^{\mathrm{a}} \cdot \mathrm{X}^{\mathrm{b}-1} \text {, }
$$

em que $\mathrm{Y}^{\prime}=$ conteúdos de energia, proteína ou de cada macromineral, no ganho, ou exigências líquidas para ganho de peso; a e b = intercepto e coeficiente de regressão, respectivamente, das equações de predição do conteúdo corporal de energia, proteína e macrominerais; $\mathrm{X}=\mathrm{PCVZ}$ (kg).

Para conversão do PV em PCVZ, foram calculadas as relações entre o PCVZ e o PV dos animais mantidos no experimento, dentro de cada classe sexual, que foram, então, utilizadas para conversão das exigências para ganho de PCVZ em exigências para ganho de PV.

Foram ajustadas equações de regressão entre a energia retida (Mcal/dia) e o ganho diário de PCVZ (GPCVZ, kg/dia), para determinado PCVZ metabólico ( $\left.\mathrm{kg}^{0,75}\right)$, conforme preconizado pelo NRC (1984). Segundo o método do NRC (1984), obtém-se equação de regressão entre o logaritmo da ER/kg PCVZ ${ }^{0,75}$ em relação ao logaritmo do ganho de peso de corpo vazio, segundo o modelo:

$\log \left(E R / P C V Z Z^{0,75}\right)=b \times \log$ GPCVZ + a.

A partir dessa equação, obteve-se a relação entre a ER em função do PCVZ metabólico e do GPCVZ, da seguinte forma:

$$
\mathrm{ER}(\text { Mcal } / \text { dia })=10^{\mathrm{a}} \times \mathrm{PCVZ}^{0,75} \times \mathrm{GPCVZ}^{\mathrm{b}} .
$$

Assim, a equação final foi representada pelo modelo: $\mathrm{ER}(\mathrm{Mcal} / \mathrm{dia})=\mathrm{c} \times \mathrm{PCVZ}^{0,75} \times \mathrm{GPCVZ}^{\mathrm{b}}$.

As exigências de energia metabolizável para mantença foram estimadas a partir da relação entre a energia retida (ER, Mcal/kg PCVZ ${ }^{0,75}$ ) e o consumo de energia metabolizável (CEM, Mcal/kg PCVZ ${ }^{0,75}$ ), segundo o modelo: $\mathrm{ER}(\mathrm{Mcal} / \mathrm{kg} P C V Z, 75)=\beta_{1} \times \mathrm{CEM}\left(\mathrm{Mcal} / \mathrm{kg} \mathrm{PCVZ}^{0,75}\right)+\beta_{0}$, em que $\beta_{1}$ representa a eficiência de uso da energia metabolizável para ganho de peso. Igualando-se a ER a 0 na equação acima, foi obtido o consumo de energia em que a retenção de energia é nula, representando as exigências de energia metabolizável para mantença (EMm). Assim, a EMm foi obtida pela razão entre os coeficientes $\beta_{0}$ e $\beta_{1}$ da equação acima $\left(E M m=\beta_{0} / \beta_{1}\right)$. Para obtenção dos parâmetros $\beta_{0}$ e $\beta_{1}$ da equação acima, foi utilizado o método da regressão ortogonal, conforme preconizado por Fuller (1987), uma vez que se assumiu a existência de erros associados às duas variáveis (ER e CEM). A estimação dos parâmetros da regressão ortogonal é realizada visando reduzir a distância perpendicular entre os valores estimados e a reta dos valores observados, e essa redução não depende de um eixo específico (Dissanaike \& Wang, 2001).

Os parâmetros da equação foram obtidos da seguinte forma:

$$
\begin{gathered}
\beta_{0}=\bar{Y}-\beta_{1} \bar{X} \\
\beta_{1}=\frac{\sigma_{y}^{2}-\sigma_{x}^{2}+\left(\left(\sigma_{y}^{2}-\sigma_{x}^{2}\right)^{2}+4 \sigma_{x y}^{2}\right)^{0.5}}{2 \sigma_{x y}^{2}}
\end{gathered}
$$

em que: $\bar{X}=$ média da variável independente (consumo de energia metabolizável); $\bar{Y}$ = média da variável dependente 
(energia retida); $\sigma_{x}^{2}=$ variância de $X ; \sigma_{y}^{2}=$ variância de $Y$; $\sigma_{\mathrm{xy}}=$ covariância entre $\mathrm{X}$ e $\mathrm{Y}$.

Foram construídas equações de regressão em relação ao CEM separadamente para cada classe sexual.

O consumo de energia metabolizável foi obtido a partir do consumo de energia digestível, multiplicado pelo fator 0,82 (NRC, 2000). O consumo de energia digestível foi obtido a partir dos teores de nutrientes digestíveis totais, multiplicados pelos seus respectivos valores calóricos, obtidos em experimento paralelo com animais provindos do mesmo lote (Marcondes et al., 2008), utilizando-se coleta total de fezes, cujos valores de NDT foram de 71,01; 72,79 e 72,64\% para machos não-castrados, machos castrados e fêmeas na dieta com $1,00 \%$ de concentrado, respectivamente, e de 73,$01 ; 70,60$ e $73,72 \%$ para as mesmas classes na dieta de $1,25 \%$ de oferta de concentrado.

Para estimação da eficiência de conversão das exigências líquidas de proteína em exigências de proteína metabolizável, foi obtida uma equação para proteína retida (PBret/PCVZ) em relação ao consumo de proteína metabolizável (CPMet/ PCVZ). O coeficiente angular dessa equação correspondeu à essa eficiência. Foi obtida uma equação conjunta para as três classes sexuais.

O consumo de proteína metabolizável foi calculado como a soma da proteína digestível degradada no rúmen (PDR) e da proteína digestível não-degradada no rúmen. A PDR foi obtida a partir do consumo de NDT (NRC, 2001), ou seja, $130 \mathrm{~g}$ de PB microbiana/kg de NDT consumido - e multiplicada pelo fator 0,64 na transformação para proteína verdadeira microbiana digestível. Foi considerado o valor de $80 \%$ de digestibilidade para a PNDR.

Os dados obtidos neste experimento foram analisados em conjunto com os dados de mantença (provenientes de 12 observações, quatro de cada classe sexual) usados por Paulino (2006) em animais da mesma fazenda recebendo mesmo manejo alimentar, uma vez que neste trabalho não houve animais alimentados em nível de mantença.

Os resultados foram interpretados estatisticamente por meio de análises de variância e regressão utilizando-se o programaSAS (1997).

\section{Resultados e Discussão}

Para obtenção do peso de corpo vazio inicial dos animais (PCVZi), foi utilizada a relação média PCVZ/PV obtida no abate dos animais-referência. A classe sexual não influenciou $(\mathrm{P}>0,05)$ a relação $\mathrm{PCVZ} / \mathrm{PV}$, cujo valor médio foi de 0,874 , menor que o valor de 0,891 sugerido pelo NRC (1996). Véras et al. (2000), também utilizando bovinos Nelore, encontraram valor de 0,844 .
$\mathrm{Na}$ conversão das exigências para ganho de PCVZ (GPCVZ) em exigências para ganho de peso vivo (GPV), foram utilizados os valores médios de 0,949 para machos castrados, 1,014 para machos não-castrados e 1,011 para fêmeas, que não diferiram entre si $(\mathrm{P}>0,05)$ pela análise de variância. Pelo intervalo de confiança, a $5 \%$ de probabilidade, para a relação GPCVZ/GPV (IC $=0,965 \leq \mathrm{GPCVZ/}$ GPV $\leq 1,017$ ), observou-se que a relação não diferiu estatisticamente de 1, assim, nas condições deste trabalho, os mesmos valores encontrados para os requisitos líquidos para ganho de $1 \mathrm{~kg}$ de $\mathrm{PV}$ podem ser utilizados para os requisitos para ganho de $1 \mathrm{~kg}$ de PVCZ.

As equações se ajustaram satisfatoriamente aos dados referentes aos conteúdos de minerais, com exceção do cálcio, uma vez que os coeficientes de determinação foram relativamente baixos (Tabela 4). Paulino et al. (2004a), Paulino et al. (1999) e Véras et al. (2001) observaram que os coeficientes de correlação foram baixos para o magnésio e para o sódio, fato não observado neste experimento.

Os resultados indicam que as exigências líquidas, em g/kg GPCVZ, para os macrominerais estudados diminuíram com o aumento do peso vivo (Tabela 5). À medida que o peso dos animais aumentou, a participação no tecido ósseo do corpo vazio diminuiu e a participação de outros tecidos aumentou, principalmente a do tecido adiposo. Como o tecido ósseo é o que possui a maior parte dos minerais presentes no corpo, as exigências dos minerais diminuem com a menor participação desse tecido no corpo. Diversos autores observaram comportamento semelhante (Lana et al., 1992a; Paulino et al., 1999; Véras et al., 2001; Silva et al., 2002a; Veloso et al., 2002; Paulino et al., 2004a).

O ARC (1980) recomenda exigência fixa de cálcio de $14 \mathrm{~g} / \mathrm{kg}$ de GPCVZ, enquanto o AFRC (1991), considerando o peso vivo à maturidade de $450 \mathrm{~kg}$ e a relação GPV/GPCVZ $=1$, recomenda para animais de 250 a $450 \mathrm{~kg}$ exigências líquidas de 11,19 a 9,83 g de $\mathrm{Ca} / \mathrm{kg}$ de GPCVZ. Considerando um animal de $400 \mathrm{~kg}$, Paulino et al. (2004a) encontraram valor de 11,67 g, Paulino et al.(1999) 8,63 g, Véras et al. (2001) 8,18g e Silva et al. (2002a) 11,19 g de Ca/kg de GPCVZ. Portanto, os valores encontrados neste experimento estão bem próximos à maioria dos dados encontrados na literatura.

Para o fósforo os valores encontrados neste experimento também estão de acordo com a literatura. Para um animal de $400 \mathrm{~kg}$, por exemplo, ganhando $1 \mathrm{~kg}$ por dia e com peso vivo à maturidade de $450 \mathrm{~kg}, \mathrm{o} A R C(1980)$ recomenda 5,45 g/kg de GPCVZ, o AFRC (1991) 5,96, o NRC (1996) 8,0, Lanaetal.(1992a) 5,82,Fontes(1995) 5,39ePaulinoet al.(2004a) $5,62 \mathrm{~g} / \mathrm{kg}$ de GPCVZ.

As exigências líquidas de magnésio encontradas neste trabalho variaram, em média, de 0,29 e $0,21 \mathrm{~g} / \mathrm{kg}$ de GPCVZ, 
quando o peso vivo do animal aumentou de 250 para $450 \mathrm{~kg}$. Esses valores estão de acordo com aqueles encontrados por outros autores (Lana et al., 1992a; Fontes 1995; Paulino et al., 2004a). O ARC (1980) recomenda exigência

Tabela 4 - Parâmetros da regressão do logaritmo dos conteúdos de minerais $(\mathrm{kg})$ no corpo vazio em função do logaritmo do peso de corpo vazio $(\mathrm{kg})$ para as três classes sexuais

\begin{tabular}{|c|c|c|c|}
\hline \multirow[t]{2}{*}{ Classe sexual } & \multicolumn{2}{|c|}{ Parâmetro } & \multirow[b]{2}{*}{$r^{2}$} \\
\hline & $\begin{array}{c}\text { Intercepto } \\
\quad\left(\beta_{0}\right)\end{array}$ & $\begin{array}{l}\text { Coef. inclinação } \\
\left(\beta_{1}\right)\end{array}$ & \\
\hline \multicolumn{4}{|c|}{ Cálcio } \\
\hline Machos não-castrados & $-0,2122$ & 0,4469 & 0,6635 \\
\hline Machos castrados & $-0,3782$ & 0,4965 & 0,5612 \\
\hline Fêmeas & $-0,6781$ & 0,6018 & 0,3401 \\
\hline \multicolumn{4}{|c|}{ Fósforo } \\
\hline Machos não-castrados & $-1,2383$ & 0,6699 & 0,8858 \\
\hline Machos castrados & $-1,1360$ & 0,6329 & 0,6607 \\
\hline Fêmeas & $-1,2232$ & 0,6481 & 0,7189 \\
\hline \multicolumn{4}{|c|}{ Sódio } \\
\hline Machos não-castrados & $-2,8473$ & 1,0092 & 0,9845 \\
\hline Machos castrados & $-2,7750$ & 0,9830 & 0,9361 \\
\hline Fêmeas & $-2,5554$ & 0,8847 & 0,9436 \\
\hline \multicolumn{4}{|c|}{ Potássio } \\
\hline Machos não-castrados & $-2,0604$ & 0,7311 & 0,9503 \\
\hline Machos castrados & $-2,1991$ & 0,7874 & 0,9764 \\
\hline Fêmeas & $-1,9995$ & 0,6948 & 0,9194 \\
\hline \multicolumn{4}{|c|}{ Magnésio } \\
\hline Machos não-castrados & $-2,0111$ & 0,4924 & 0,5674 \\
\hline Machos castrados & $-1,9646$ & 0,4683 & 0,7674 \\
\hline Fêmeas & $-2,1311$ & 0,5118 & 0,8552 \\
\hline
\end{tabular}

fixa de 0,45 g/kg de PCVZ, independentemente do peso do animal, valor superior aos encontrados na literatura.

As exigências líquidas de potássio variaram em média de 1,47 a 1,14 g/kg GPCVZ quando o PV dos animais variou de 250 para $450 \mathrm{~kg}$. Esses valores estão de acordo com aqueles encontrados por Lana et al. (1992a) e Fontes (1995), mas são superiores aos obtidos por Paulino et al. (2004a) e menores que a recomendação do ARC (1980). Para o sódio, os valores encontrados neste experimento estão de acordo com o ARC (1980), mas são maiores que aqueles encontrados por Paulino et al. (2004a), Lana et al. (1992a) e Fontes (1995).

De modo geral, as exigências de macrominerais para bovinos zebuínos com predominância de sangue Nelore são menores que aquelas apresentadas por sistemas de exigências nutricionais já consagrados - como ARC (1980), AFRC (1991) e NRC (1996) -, o que evidencia a importância de se ampliar esse tipo de estudos no Brasil e de lançar tabelas de exigências formuladas apenas com dados obtidos no Brasil. Acredita-se que esse tipo de tecnologia poderá, além de melhorar a eficiência em sistemas agropecuários nacionais, reduzir custos para produtores em nível de campo.

Foram construídas equações do logaritmo do conteúdo de gordura (kg), energia (Mcal) ou proteína (kg) em função do logaritmo do peso de corpo vazio (kg), dentro de cada classe sexual, usando os dados dos animais alimentados com os dois níveis de oferta de concentrado e o grupo referência (Tabela 6).

De acordo com as equações obtidas, observou-se aumento nos conteúdos corporais de gordura e energia,

Tabela 5 - Exigências líquidas de macrominerais para machos não-castrados, machos castrados e fêmeas Nelore

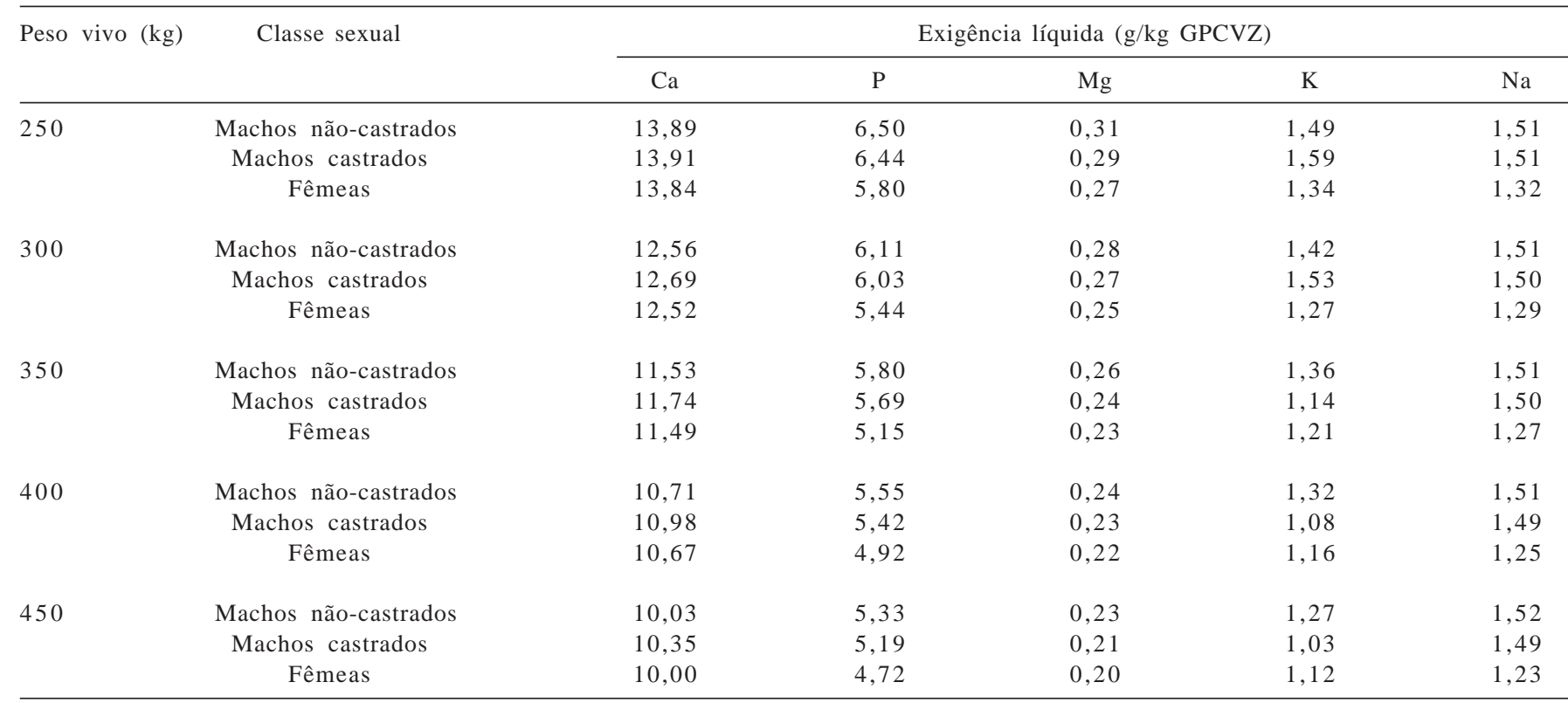


para a três classes sexuais, à medida que o peso vivo aumentou de 300 para 450 kg. Observou-se também que os conteúdos de gordura e energia foram numericamente superiores nas fêmeas em relação aos machos castrados, que, por sua vez, foram superiores aos dos machos não-castrados. Isso demonstra como as fêmeas tendem a depositar gordura mais precocemente, seguidas dos animais castrados, o que reflete nas exigências de energia líquida para ganho (Tabela 7), que são maiores nas fêmeas, seguidas pelos machos castrados e, por último, pelos não-castrados.

Tabela 6 - Parâmetros de regressão do logaritmo dos conteúdos de gordura, energia e proteína no corpo vazio em função do logaritmo do peso de corpo vazio de bovinos Nelore de três classes sexuais

\begin{tabular}{|c|c|c|c|}
\hline \multirow[t]{2}{*}{ Classe sexual } & \multicolumn{2}{|c|}{ Parâmetro } & \multirow[b]{2}{*}{$\mathrm{r}^{2}$} \\
\hline & $\begin{array}{l}\text { Intercepto } \\
\qquad\left(\beta_{0}\right)\end{array}$ & $\begin{array}{l}\text { Coef. inclinação } \\
\qquad\left(\beta_{1}\right)\end{array}$ & \\
\hline \multicolumn{4}{|c|}{ Gordura (kg) } \\
\hline Machos não-castrados & $-3,6717$ & 2,1467 & 0,9181 \\
\hline Machos castrados & $-4,3398$ & 2,4493 & 0,9469 \\
\hline Fêmeas & $-3,4286$ & 2,1222 & 0,9107 \\
\hline \multicolumn{4}{|c|}{ Energia (Mcal) } \\
\hline Machos não-castrados & $-1,0914$ & 1,5975 & 0,9663 \\
\hline Machos castrados & $-1,5490$ & 1,7963 & 0,9730 \\
\hline Fêmeas & $-1,2869$ & 1,7151 & 0,9338 \\
\hline \multicolumn{4}{|c|}{ Proteína (kg) } \\
\hline Machos não-castrados & $-0,3729$ & 0,8497 & 0,8836 \\
\hline Machos castrados & 0,0765 & 0,6654 & 0,8530 \\
\hline Fêmeas & $-0,0928$ & 0,7226 & 0,8609 \\
\hline
\end{tabular}

Considerando um animal de $400 \mathrm{~kg}$, os machos castrados foram 23\% mais exigentes que os não-castrados e 11\% menos exigentes que as fêmeas. Segundo o NRC (2000), machos castrados são $18 \%$ mais exigentes que os nãocastrados e 18\% menos exigentes que as fêmeas em relação às exigências líquidas de energia para ganho de peso. A diferença nas exigências de energia entre machos nãocastrados e castrados aumentou de 16 para 26\% quando o peso variou de 300 para $450 \mathrm{~kg}$, evidenciando que animais não-castrados são mais tardios na deposição de gordura que os castrados. Por outro lado, a diferença entre animais castrados e fêmeas diminuiu de 13,5 para $10 \%$, nessa mesma variação de peso vivo, comprovando que machos castrados começam a depositar gordura de forma mais pronunciada quando se tornam mais pesados.

A partir dos dados de energia retida (ER, Mcal/dia), peso de corpo vazio médio metabólico $\left(\mathrm{PCVZ}^{0,75}, \mathrm{~kg}^{0,75}\right)$ e do ganho de peso de corpo vazio (GPCVZ, kg/dia) dos animais, construíram-se equações para estimar a energia retida a partir desses dois parâmetros. Assim, foram construídas equações para cada classe sexual: Machos não-castrados: $\mathrm{ER}=0,0547 \times \mathrm{PCVZ}^{0,75} \times \mathrm{GPCVZ}^{1,1037}$ $\mathrm{r}^{2}=0,9895$

Machos castrados: $\mathrm{ER}=0,0738 \times \mathrm{PCVZ}^{0,75} \times \mathrm{GPCVZ}^{0,9688}$ $\mathrm{r}^{2}=0,9882$

Fêmeas: $\mathrm{ER}=0,1026 \times \mathrm{PCVZ}^{0,75} \times \mathrm{GPCVZ}^{1,0408} \mathrm{r}^{2}=0,9745$

Teoricamente, o coeficiente da variável GPCVZ deveria ser sempre maior que 1 , pois, como aumenta o ganho de peso de corpo vazio, o animal deveria aumentar a deposição

Tabela 7 - Exigências líquidas de energia, conteúdo de gordura no ganho de peso do corpo vazio e exigências líquidas de proteína de machos não-castrados, machos castrados e fêmeas Nelore

\begin{tabular}{|c|c|c|c|c|}
\hline PV (kg) & Classe sexual & $\begin{array}{l}\text { Exigências líquidas de energia } \\
\text { (Mcal/kg GPCVZ) }\end{array}$ & $\begin{array}{l}\text { Conteúdo de gordura } \\
\text { (g/kg GPCVZ) }\end{array}$ & $\begin{array}{c}\text { Exigências líquidas de proteína } \\
\text { (g/kg GPCVZ) }\end{array}$ \\
\hline \multirow[t]{2}{*}{250} & Machos não-castrados & 3,251 & 209,258 & 166,590 \\
\hline & Fêmeas & 4,653 & 388,588 & 146,621 \\
\hline \multirow[t]{2}{*}{300} & Machos não-castrados & 3,619 & 273,107 & 155,767 \\
\hline & Machos castrados & 4,224 & 350,288 & 123,780 \\
\hline \multirow[t]{3}{*}{350} & Machos não-castrados & 3,969 & 325,912 & 152,200 \\
\hline & Machos castrados & 4,776 & 437,977 & 117,557 \\
\hline & Fêmeas & 5,351 & 493,415 & 118,901 \\
\hline \multirow[t]{2}{*}{400} & Machos não-castrados & 4,298 & 379,840 & 149,176 \\
\hline & Machos castrados & 5,312 & 531,494 & 112,420 \\
\hline 450 & Fêmeas & 6,405 & 654,176 & 110,895 \\
\hline
\end{tabular}


e exigência de energia. Entretanto, provavelmente em virtude do pequeno número de repetições (seis), não foi possível encontrar um coeficiente maior que 1 para machos castrados. Esse fato aconteceu de forma semelhante com outros autores (Paulino et al., 2004b; Silva et al., 2002b), porém, ao se agrupar grande quantidade de dados (Valadares Filho et al., 2006; NRC, 1996), o coeficiente para a variável GPCVZ ultrapassou o valor um.

Considerando como referência um animal com peso de corpo vazio de $300 \mathrm{~kg}$ e taxa de ganho de peso de corpo vazio de $0,7 \mathrm{~kg} /$ dia, obtiveram-se valores de 2,66; 3,77 e $5,10 \mathrm{Mcal} /$ dia para machos não-castrados, machos castrados e fêmeas, respectivamente. Outros autores encontraram valores similares ao fazerem uma simulação semelhante. Paulino(2006) encontrou valores de 2,66;3,36 e 3,67 Mcal/dia para as mesmas classes sexuais e mesma faixa de peso e desempenho e, segundo o NRC (2000), esses valores seriam de 2,54; 3,10 e 3,65 Mcal/dia, respectivamente. Utilizando as Tabelas Brasileiras de Exigências Nutricionais de Zebuínos (Valadares Filho et al., 2006), obtêm-se exigências de 2,58; 2,96 e 3,58 Mcal/dia para machos nãocastrados, machos castrados e fêmeas, respectivamente. Trabalhando com animais castrados, para essa mesma simulação, Paulino et al. (2004b) sugeriram exigência de 3,67 Mcal/dia e Tedeschi et al. (2002) de 4,08. Valores semelhantes aos obtidos neste trabalho foram encontrados por outros autores, porém em machos não-castrados. Véras et al. (2000) e Silva et al. (2002b) sugeriram exigência de 2,10 Mcal/dia para machos Nelore não-castrados com $300 \mathrm{~kg}$ de peso de corpo vazio e GPCVZ de 0,7 kg/dia.

Apenas os valores de exigências de energia líquida para ganho das fêmeas foram superiores aos encontrados na literatura, um reflexo da maior deposição de gordura e desempenho dos animais em relação aos outros dados citados. O requerimento de energia para mantença tem sido definido como o consumo de energia metabolizável (CEM) por dia em que o balanço energético do animal se torna nulo ou zero (Dawson \& Steen, 1998). Essa exigência pode ser obtida montando uma equação da energia retida (ER) em relação ao consumo de energia metabolizável (Figura 1). Igualando-se a retenção de energia a 0 , obtêm-se os valores de exigência metabolizável para mantença (Tabela 8). Paulino (2006) encontrou valores de EMm de 103,26; 100,57 e $113,81 \mathrm{kcal} / \mathrm{kg} \mathrm{PCVZ}^{0,75}$ para machos não-castrados, machos castrados e fêmeas, respectivamente, e Valadares Filho et al. (2006), em compilação de dados da literatura nacional obtidos com animais zebuínos, encontraram valores de 109,$35 ; 109,77$ e $108,22 \mathrm{kcal} / \mathrm{kg} \mathrm{PCVZ}^{0,75}$ para essas mesmas classes sexuais.

A concentração de proteína no corpo vazio dos animais das três classes sexuais diminuiu conforme o peso de corpo vazio aumentou, uma consequência da maior
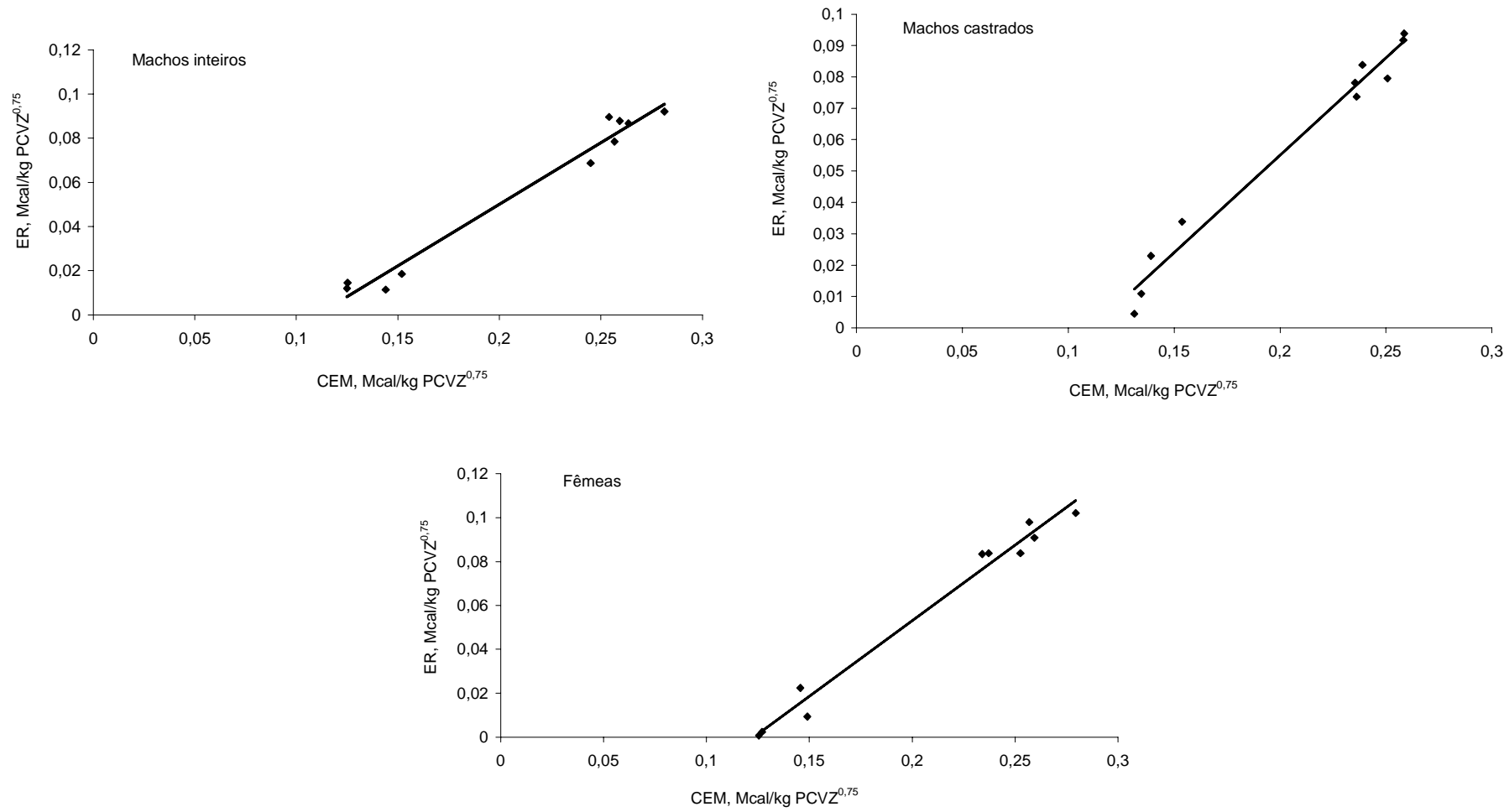

Figura 1 - Relação entre energia retida (ER) e consumo de energia metabolizável (CEM) em bovinos Nelore de três classes sexuais, obtido pelo método da regressão ortogonal. 
Tabela 8 - Regressões da energia retida (ER, Mcal/kg PCVZ ${ }^{0,75}$ ) em função do consumo de energia metabolizável (CEM, $\mathrm{Mcal} / \mathrm{kg} \mathrm{PCVZ}^{0,75}$ ) e estimativa das exigências de energia metabolizável para mantença (EMm, kcal/kg $\mathrm{PCVZ}^{0,75}$ ) de bovinos Nelore de três classes sexuais

\begin{tabular}{lcccc}
\hline Classe sexual & Intercepto & Inclinação & $\mathrm{r}^{2}$ & $\mathrm{EMm}$ \\
\hline Machos não-castrados & $-0,0557$ & 0,5272 & 0,9748 & 105,06 \\
Machos castrados & $-0,0637$ & 0,5940 & 0,9770 & 107,23 \\
Fêmeas & $-0,0740$ & 0,6431 & 0,9819 & 115,13 \\
\hline
\end{tabular}

deposição de gordura nas fases mais tardias de crescimento dos animais, fazendo com que as exigências líquidas de proteína para ganho também diminuíssem à medida que os animais foram ficando mais pesados (Tabela 7).

Assim como para energia, os valores encontrados foram semelhantes aos descritos por Paulino (2006). Outros autores, trabalhando com animais Nelore castrados, também encontraram valores similares (Paulino et al., 2004c; Lana et al., 1992b; Fontes 1995). Em relação às fêmeas, Borges (2000) obtiveram em fêmeas Guzerá de 300 kg em torno de 126,04 g/kg GPCVZ, bem semelhantes aos 124,10 g “mistura ideal” de aminoácidos. Assim, pode-se afirmar que os valores de energia são fortemente influenciados pela qualidade da fonte de proteína não-degradada no rúmen e pelo valor biológico da proteína microbiana (Oldham, 1987).

\section{Conclusões}

As exigências de energia líquidas para ganho aumentam de acordo com o peso vivo dos animais; são maiores em fêmeas que em machos castrados, que, por sua vez, são mais exigentes que machos não-castrados. As exigências líquidas de proteína para ganho diminuem com o aumento do peso vivo dos animais. A eficiência de uso da proteína metabolizável em bovinos Neloreéde aproximadamente 50\%.

\section{Literatura Citada}

AGRICULTURAL AND FOOD RESEARCH COUNCIL - AFRC. A reappraisal of the calcium and phosphous requirements of sheep and cattle. 6.ed. Nutrition Abstract and Reviews (Series B). Wallingford: 1991. p.573-612.

AGRICULTURAL RESEARCH COUNCIL - ARC. The nutrient requirements of ruminants livestock. London: 1980. 351p.

BORGES, A.L.C.C. Exigências nutricionais de proteína e energia de novilhas das raças Guzerá e Holandesa. 2000. 90f. Tese (Doutorado em Zootecnia) - Universidade Federal de Minas Gerais, Belo Horizonte, 2000.

DAWSON, L.E.R.; STEEN, R.W.J. Estimation of maintenance energy requirements of beef cattle and sheep. Journal of Agriculture Science, v.131, p.477-485, 1998.

DISSANAIKE, G.; WANG, S. [2001]. A critical examination of orthogonal regression. Disponível em: <http://ssrn.com/ abstract $=407560>$. Acesso em: 15/1/2007.
FERRELL, C.L.; JENKINS, T.G. Cow tyope and nutritional environment: nutritional aspects. Journal of Animal Science, v.61, n.3, p.725-741, 1985.

FONTES, C.A.A. Composição corporal, exigências líquidas de nutrientes para ganho de peso e desempenho produtivo de animais zebuínos e mestiços europeu-zebu. Resultados experimentais. In: SIMPÓSIO INTERNACIONAL SOBRE EXIGÊNCIAS NUTRICIONAIS DE RUMINANTES, 1., 1995, Viçosa, MG. Anais... Viçosa, MG: Universidade Federal de Viçosa, 1995. p.419-455.

FULLER, W.A. Measurement error models. New York: John Wiley and Sons, 1987.

LANA, R.P.; FONTES, C.A.A.; PERON, A.J. et al. Composição corporal e do ganho de peso e exigências de energia, proteína e macroelementos minerais ( $\mathrm{Ca}, \mathrm{P}, \mathrm{Mg}$, $\mathrm{Na}$ e $\mathrm{K}$ ) de novilhos de cinco grupos raciais. 3. Conteúdo corporal e do ganho de peso e exigências de macroelementos minerais. Revista Brasileira de Zootecnia, v.4, p.538-544, 1992a.

LANA, R.P.; FONTES, C.A.A.; PERON, A.J. et al. Composição corporal e do ganho de peso e exigências de energia, proteína e macroelementos minerais ( $\mathrm{Ca}, \mathrm{P}, \mathrm{Mg}, \mathrm{Na}$ e $\mathrm{K}$ ), de novilhos de cinco grupos raciais. I. Conteúdo corporal e do ganho de peso em gordura, proteína e energia. Revista Brasileira de Zootecnia, v.3, p.518-527, 1992b.

MARCONDES, M.I.; VALADARES FILHO, S.C.; PAULINO, P.V.R. et al. Consumo e desempenho de animais alimentados individualmente ou em grupo e características de carcaça de animais Nelore de três classes sexuais. Revista Brasileira de Zootecnia, v.37, n.12, p.2243-2250, 2008.

NATIONAL RESEARCH COUNCIL - NRC. Nutrients requirements of beef cattle. 6.ed. Washington D.C.: National Academic Press, 1984. 90p.

NATIONAL RESEARCH COUNCIL - NRC. Nutrients requirements of beef cattle. 7.ed. Washington, D.C.: National Academic Press, 1996. 242p.

NATIONAL RESEARCH COUNCIL - NRC. Nutrients requirements of beef cattle. 7.ed. Washington, D.C.: National Academic Press, 2000. 242p.

NATIONAL RESEARCH COUNCIL - NRC. Nutrient requirements of dairy cattle. 7.ed. Washinton, D.C.: National Academic Press, 2001. 381p.

OLDHAM, J.D. Efficiencies of amino acids utilization. In: JARRIGE, R.; ALDERMAN, G. (Eds.) Feed evaluation and protein requirements systems for ruminants. Luxembourg: 1987. p.171-186.

PAULINO, M.F.; FONTES, C.A.A.; JORGE, A.M. et al. Composição corporal e exigências de macroelementos minerais ( $\mathrm{Ca}, \mathrm{P}, \mathrm{Mg}$, Na e K) de bovinos não-castrados de quatro raças zebuínas. Revista Brasileira de Zootecnia, v.28, n.3, p.634-641, 1999

PAULINO, P.V.R. Desempenho, composição corporal e exigências nutricionais de bovinos Nelore de diferentes classes sexuais. 2006. 159f. Tese (Doutorado em Zootecnia) Universidade Federal de Viçosa, Viçosa, MG, 2006.

PAULINO, P.V.R.; COSTA, M.A.L.; VALADARES FILHO, S.C. et al. Exigências nutricionais de zebuínos: minerais. Revista Brasileira de Zootecnia, v.33, n.3, p.770-780, 2004a.

PAULINO, P.V.R.; COSTA, M.A.L.; VALADARES FILHO, S.C. et al. Exigências nutricionais de zebuínos: energia. Revista Brasileira de Zootecnia, v.33, n.3, p.781-791, 2004b.

PAULINO, P.V.R.; COSTA, M.A.L.; VALADARES FILHO, S.C. et al. Exigências nutricionais de zebuínos: proteína. Revista Brasileira de Zootecnia, v.33, n.3, p.759-769, 2004c.

SAINZ, R.D.; BARIONI, L.G.; PAULINO, P.V.R. et al. Growth patterns of Nellore vs. British beef cattle breeds assessed using a dynamic, mechanistic model of cattle growth and composition. In: INTERNATIONAL WORKSHOP ON MODELING NUTRIENT UTILIZATION IN FARM ANIMALS, 6., 2004., Wageningen. Proceedings... Wageningen: Wageningen University, 2004. p.160-170. 
SILVA, D.J.; QUEIROZ, A.C. Análise de alimentos (métodos químicos e biológicos). 3.ed. Viçosa, MG: Editora UFV, 2002. $165 p$.

SILVA, F.F.; VALADARES FILHO, S.C.; ITAVO, L.C.V. et al. Composição corporal e requisitos líquidos e dietéticos de macroelementos minerais de bovinos Nelore não-castrados. Revista Brasileira de Zootecnia, v.31, n.2, p.757-764, 2002a.

SILVA, F.F.; VALADARES FILHO, S.C.; ITAVO, L.C.V. et al. Composição corporal e requisitos energéticos e protéicos de bovinos Nelore, não-castrados, alimentados com rações contendo diferentes níveis de concentrado e proteína. Revista Brasileira de Zootecnia, v.31, n.1, p.503-513, 2002b.

STATISTICAL ANALYSIS SYSTEM - SAS. Institute SAS/STAT software: changes and enhancements through release 6.12. Cary: SAS Institute, 1997. 1167p.

TEDESCHI, L.O.; BOIN, C.; FOX, D.G. et al. Energy requirements for maintenance and growth of Nellore bulls and steers fed high-forage diets. Journal of Animal Science, v.80, p.16711682, 2002
VALADARES FILHO, S.C.; PAULINO, P.V.R.; MAGALHÃES, K.A. Exigências nutricionais de zebuínos e tabelas brasileiras de composição de alimentos para bovinos. 1.ed. Viçosa, MG: Suprema, 2006. 141p.

VELOSO, C.M.; VALADARES FILHO, S.C.; GESUALDI JÚNIOR, A. et al. Composição corporal e exigências líquidas e dietéticas de macroelementos minerais de bovinos $\mathrm{F} 1$ Limousin $\mathrm{x}$ Nelore não-castrados. Revista Brasileira de Zootecnia, v.31, n.3, p.1294-1301, 2002.

VÉRAS, A.S.C.; VALADARES FILHO, S.C.; COELHO DA SILVA, J.F. et al. Composição corporal e requisitos energéticos e protéicos de bovinos Nelore, inteiros, alimentados com rações contendo diferentes níveis de concentrado. Revista Brasileira de Zootecnia, v.29, n.8, p.2379-2389, 2000 (supl. 2).

VÉRAS, A.S.C; VALADARES FILHO, S.C.; SILVA, J.F.C. et al. Composição corporal e requisitos líquidos e dietéticos de macroelementos minerais de bovinos Nelore não-castrados. Revista Brasileira de Zootecnia, v.30, n.3, p.1106-1111, 2001. 